REGARDS

SUR L'ECONOMIE ALLEMAND

BULLETIN ECONOMIQUE DU CIRAC
Regards sur l'économie allemande

Bulletin économique du CIRAC

$89 \mid 2008$

Varia

\title{
Prendre la mesure de la crise
}

\section{René Lasserre}

\section{OpenEdition}

Journals

Édition électronique

URL : http://journals.openedition.org/rea/2823

DOI : 10.4000/rea.2823

ISBN : 978-2-8218-0874-4

ISSN : 1965-0787

Éditeur

CIRAC

Édition imprimée

Date de publication : 1 décembre 2008

Pagination : 1-2

ISSN : 1156-8992

Référence électronique

René Lasserre, "Prendre la mesure de la crise », Regards sur l'économie allemande [En ligne], 89 | décembre 2008, mis en ligne le 12 janvier 2009, consulté le 22 septembre 2020. URL : http:// journals.openedition.org/rea/2823 ; DOI : https://doi.org/10.4000/rea.2823 


\section{Prendre la mesure de la crise}

Après avoir longtemps résisté à la crise financière par la solidité de son économie réelle, il se confirme depuis l'été que l'Allemagne, à son tour, n'échappera pas la récession. Mais alors que la batterie de prévisions publiées au cours de l'automne pouvait encore laisser présager que l'économie allemande n'affronte qu'un recul conjoncturel modéré en 2009, il semblerait, au regard des données annoncées à la veille de Noël, que son atterrissage sera beaucoup plus brutal que prévu. Les tout derniers chiffres publiés par les instituts RWI et ifo prévoient en effet un recul de 2 à 2,2 \% du PIB en 2009, annonçant ainsi la récession la plus sévère que l'Allemagne ait connue depuis 1948.

Ces prévisions pessimistes, qui s'appuient sur le constat attendu d'un fort recul de l'activité (de l'ordre de $-1,5 \%$ ) au cours du dernier trimestre 2008 venant s'ajouter au $-0,5 \%$ du précédent, devraient être confirmées par le rapport économique que présentera le gouvernement fédéral début janvier, et laissent d'ores et déjà prévoir une dégradation préoccupante de la situation économique au premier semestre 2009. En cela, ces sombres pronostics pour l'année qui vient extrapolent sans doute un peu vite les effets à court terme de la crise financière et sousestiment sans doute les facteurs de résilience de l'économie allemande qui devraient contribuer à amortir le choc. Ainsi au plan interne, le volume élevé de l'emploi et une bonne tenue des salaires conventionnels continueront de soutenir une demande intérieure par ailleurs soulagée par la stabilisation des prix du pétrole et du gaz et une inflation modérée. Au plan externe, la baisse de l'euro se conjuguera à la compétitivité des entreprises à l'exportation, laquelle, en dépit d'un recul déjà sensible du commerce mondial, ne se dément pas.

Ces points forts de l'économie allemande ont fondé la circonspection qui a jusqu'à présent inspiré la politique économique du gouvernement allemand face à la crise. Indépendamment des contraintes systémiques qui président à une gouvernance économique polyarchique et polycentrique, celle-ci s'est davantage attachée à définir un cap partagé de politique économique et une méthodologie de lutte contre la crise, plutôt que de céder à une politique de relance européenne mal ciblée et définie dans la précipitation. Soucieuse d'utiliser au mieux les marges de manœuvre économiques et financières reconquises au prix des patients efforts des acteurs socio-économiques et des collectivités publiques, l'alliance gouvernementale doit en outre tenir compte des contraintes spécifiques d'une économie domestique largement globalisée. C'est ainsi qu'elle s'est rassemblée autour d'un ordre de priorités dans lequel le renforcement de la compétitivité durable de l'offre l'emporte sur le soutien immédiat à la demande et, par voie de conséquence, la promotion ciblée de l'investissement éclipse la stimulation multiforme et incertaine de la consommation.

Reste que ce concept de politique économique et cette hiérarchie de priorités, pour cohérents et pertinents qu'ils soient, risquent d'être mis à mal par l'enchaînement imprévisible des facteurs de crise. Comme semble le laisser percevoir la détérioration de l'activité qui s'est enclenchée au cours des derniers mois, Allemagne n'est pas à l'abri d'une 
conjonction négative de facteurs qui pourraient ébranler fortement les fondamentaux de son économie. Sa dépendance de l'exportation en biens d'équipement et de consommation durable, en particulier, la rend plus que tout autre vulnérable aux incertitudes multiples et cumulées des marchés extérieurs. Que ce soient celles du marché européen, où se conjugueront à des degrés divers selon les pays les effets de la crise financière et ceux du ralentissement mondial, ou bien celles du marché américain dans lequel l'ampleur de la crise tout autant que l'efficacité du programme du président Obama restent pour l'instant encore largement imprévisibles. Quant à l'évolution de la demande des pays émergents qui jusqu'à présent tiraient la demande mondiale, elle est encore plus incertaine lorsque l'on considère le ralentissement de la croissance chinoise, ou bien encore le recul du prix de l'énergie et des matières premières qui viendra impacter fortement la demande des pays producteurs en biens d'investissement. Si les trous d'air de la demande mondiale devaient ainsi se multiplier et le puissant moteur externe de l'industrie allemande s'en trouver progressivement essoufflé, les répercussions sur la demande intérieure pourraient très vite et durablement se faire sentir en termes de remontée du chômage et de rétraction de la consommation. Dans la perspective de l'échéance électorale de septembre, on imagine ce qu'un tel scénario, s'il devait prendre corps d'ici l'été, pourrait avoir d'incalculable dans le débat et les choix nationaux de politique économique...

C'est sans doute la raison pour laquelle la coalition gouvernementale serre à nouveau les rangs et commence à rassembler les décideurs économiques autour d'un pacte d'action concertée pour la croissance et l'emploi. Pacte déjà potentiellement scellé dans lequel, en fonction de l'évolution de la conjoncture internationale et des perspectives de l'économie américaines, l'ordre initial des priorités pourrait au besoin rapidement évoluer en faveur d'une politique de relance plus marquée de soutien à la demande intérieure et de défense de l'emploi. Cela ne signifierait pas pour autant que l'Allemagne change fondamentalement de politique, mais qu'au gré des nécessités elle mettra à profit, au moment voulu, les marges de manœuvre qu'elle aura su préserver pour passer le cap et renouer avec la croissance.

Quel que soit le scénario, il n'aura pas été inutile, et encore moins contraire aux intérêts de l'économie européenne, que les responsables de la première économie d'Europe, plutôt que de brûler prématurément leur cartouches, se soient donné le temps de réfléchir et de prendre la véritable mesure de la crise.

René Lasserre, le 16 décembre 2008 